\title{
Cross-linked enzyme lyophilisates (CLELs) of urease: A new method to immobilize ureases
}

\author{
Tugce Akkas $^{\mathrm{a}, *, 1}$, Anastasia Zakharyuta ${ }^{\mathrm{b}}$, Alpay Taralp ${ }^{\mathrm{a}}$, Cleva W. Ow-Yang ${ }^{\mathrm{a}}$ \\ ${ }^{a}$ Sabanci University, Materials Science and Nano-Engineering Program, 34956 Tuzla, Istanbul, Turkey \\ ${ }^{\mathrm{b}}$ Sabanci University, Molecular Biology, Genetics and Bioengineering Program, 34956 Tuzla, Istanbul, Turkey
}

\section{A R T I C L E I N F O}

\section{Keywords:}

Enzyme immobilization

Urease

Enzyme aggregates

Lyophilisates

Cross-linking

Recyclable catalyst

\begin{abstract}
A B S T R A C T
In this study, we presented a new approach for immobilizing JBU (Jack bean urease), by producing urease crosslinked enzyme lyophilisates (CLELs). Through the use of bovine serum albumin (BSA), lyophilisation, crosslinking with dextran polyaldehyde (DPA), and optimizing cross-linker $\mathrm{pH}$, the urease-CLELs produced show an increase in relative catalytic activity that is 1.47 times higher than that of free urease, while remaining stable up to temperatures of $85^{\circ} \mathrm{C}$. Urease-CLEL activity increases in direct proportion with the increasing BSA content due to the offered additional lysine (Lys) groups which are potential cross-linking points providing better immobilization and retention of JBU, while lyophilisation also enables stabilization by eliminating solvating water molecules and intra-molecular reactions that may block the cross-linking residues. Two most commonly used cross-linkers that are reacting with the available Lys groups, i.e.glutaraldehyde (GA) and bulkier alternative DPA, have been selected for the immobilization of urease. The catalytic activity increase with DPA suggests an improved access to the active site through hindering blockage, while the increase with alkaline $\mathrm{pH}$ of the crosslinkers indicates decreased buffer inhibition. The long lifetime (113\% residual activity after 4 weeks), recyclability $\left(132 \%\right.$ residual activity after 10 cycles) and thermal stability ( $276 \%$ relative activity at $\left.85^{\circ} \mathrm{C}\right)$ of these urease-CLELs demonstrate that they are technologically attractive as green biocatalysts, while our immobilization approach offers an alternative to conventional methods for proteins that are difficult to immobilise.
\end{abstract}

\section{Introduction}

Transitioning to environmentally greener and lower-cost processing is a key issue for pharmaceutical and chemical industries in the $21^{\text {st }}$ century. To address this need, bio-catalysis offers important industrial advantages, which are met viadeveloping enzyme immobilization techniques to bypass the inherent drawbacks of free enzymes. The main aim of such techniques has been to enhance the enzymatic properties and improve enzyme stability under application conditions, such as temperature, $\mathrm{pH}$, ionic strength, organic solvent, which differ from that of the native protein [1] and also solve the protein solubility problem which enables the reusability of the enzyme [2]. Furthermore, immobilization should also increase shelf life and enable reusability of the catalyst, while retaining catalytic activity [3-5], in some cases increasing the enzyme activity viapreventing enzyme inhibition [6], and also enhancing enzyme specificity and selectivity [7]. Many approaches have successfully attained these goals by physical adsorption, encapsulation, surface immobilization and cross-linking [8-13].

Because carrier-bound immobilized enzymes require a complex synthesis protocol, including binding to an inactive mass as a carrier along with screening, the carrier-free immobilization of enzymes offers an attractive alternative with advantages of lower cost and applicability to a broader spectrum of enzymes [14].

Examples of carrier-free immobilized structures include cross-linked enzymes [15,16]. Among these, cross-linked enzyme crystals (CLEC) [17], offer a stable formulation with pure enzyme content, implying a high catalyst-to-weight ratio and enhance catalytic activity, in addition to their use as industrial biocatalysts [18]. CLEC technique involves a laborious synthesis procedure, starting with enzymes of high purity, and producing low yields-all of which entails elevated cost for large-

\footnotetext{
Abbreviations: JBU, jack bean urease; BSA, bovine serum albumin; CLEL, cross-linked enzyme lyophilisate; CLEC, cross-linked enzyme crystal; CLEA, cross-linked

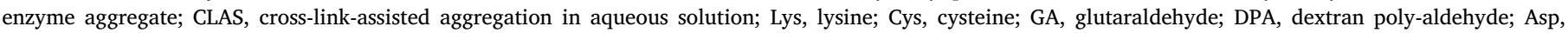
aspartic acid; Glu, glutamic acid

* Corresponding author.

E-mail address: tugceakkas@sabanciuniv.edu (T. Akkas).

${ }^{11}$ Present address: Koc University Surface Science and Technology Center (KUYTAM), Rumelifeneri Yolu, Sariyer, 34450, Istanbul, Turkey.
} 
volume processing. Moreover, this technique is not universally applicable, limited to only certain (crystallisable) enzymes [19-22].

These drawbacks of CLECs were partially addressed by cross-linked enzyme aggregate (CLEA) technology [23]. CLEAs retain excellent stability, while being based on a facile synthesis process that can also be applied to a wide range of proteins [24]. The aggregation and crosslinking steps permit retention and, in many cases, improvement of biological activity [25-29]. The use of native proteins has led to poor stability, recoverability, bioavailability, short half-life, and hydrolytic instability-all of which have been resolved by the development of cross-linked crystals and aggregates. CLEAs yield chemically robust and long-lived catalytic enzyme products.

Because both CLECs and CLEAs are not available for long-term use in industrial tanks, due to their fragility, they should be immobilized to increase durability [2]. Using an inert protein or polymer is effective, but in CLEA technology, porous supports may result in restricted diffusivity [2]. The micron-and-larger size of CLEC and CLEA products offers new challenges, such as mass-transport limitations in solutions, reduced access to catalytic triads, restricted catalytic turnover due to cross-linking, and poor bio-absorptivity. To circumvent these problems, our group has developed methods for preparing cross-linked protein nanocrystals and nanoaggregates [30]. Moreover, in the recent years, magnetic CLEAs (m-CLEAs) have been introduced with the addition of magnetic nano-particles, which are easier to recover in industrial settings for improved recyclability [31].

The general applicability of typical CLEA methods has occasionally been challenged by protein-specific anomalies. The simple, semi-specific, chemical cross-linking of protein aggregates precipitating out of solution adversely impacts the intrinsic structural and functional characteristics desirable for aggregation and cross-linking, hindering efficacy and bioactivity [30]. Prior work in our group had partially addressed the aggregation resistance by cross-link-assisted aggregation in aqueous solution (CLAS) (see Supplementary Material). However, the inefficiency of this approach for urease motivated the development of cross-linked enzyme lyophilisates (CLEL), which are incorporated in place of crash-precipitated aggregates to increase the low aggregation efficiency and activity. We hypothesised that the aggregate state could be achieved through lyophilisation [32], when crash precipitation did not yield the desired result. In this procedure, optimally formulated protein solutions were lyophilised and immersed in a medium suitable for further cross-linking, yielding cross-linked enzyme lyophilisates (CLEL). Optimization of this new method has generally led to higher overall yield for all formulations tested, with more controllable enzymatic activity and producing an easy-to-handle, final product.

We summarize all of the cross-linking methods described below in Fig. 1: CLECs, CLEAs, the CLAS method and CLELs.

As the first crystallized enzyme [33] and the first known Ni-containing metalloenzyme [34], urease is used for urea content analysis and the removal of urea from artificial kidney dialysates [35], production of ammonia or carbon dioxide through urea hydrolysis [36], insecticide in agriculture [37] and urea determination by a biosensor in the form of immobilised urease [38] For this work, we have chosen the non-glycosylated [39] and homo-oligomeric plant urease JBU (Jack bean urease), which has a hexameric structure, in which each sub-unit contains two $\mathrm{Ni}$ ions ( $\mathrm{Ni1}$ and $\mathrm{Ni2}$ ) that contribute to the catalytic reactive function (see Fig. 2) [40,41]. The structure of a single active site of JBU is composed of His519, His545, Lys490 residues liganded to Ni1 and His407, His409, Asp 633, Lys490 residues liganded to Ni2 [40]. The Lys490 residue is carbamylated and involves a bridge formation between two Ni residues [40] (Fig. 2d).

The hydrolysis of urea is catalysed by urease to yield ammonia and carbamate molecules, followed by the decomposition of carbamate into ammonia and bicarbonate [42], and the efficiency is determined by the active site structure and resulting mobility of the flap regulating access to the active site. In the crystal structure of JBU, this mobile flap serves as a gate to the active site, controlling admittance of the substrate urea
[44] and the release of reaction by-products [40,45]. The substrate urea binds to the $\mathrm{Ni}$ ions in the active site and undergoes hydrolysis upon closing of the flap. After the reaction, the flap opens to release the byproducts and accept a new urea molecule to continue with another catalytic cycle [43]. Inhibitors, by binding to the active site, are used to tune the catalytic activity of urease, viainducing changes to the site geometry. Such inhibitor-induced changes also influence active site access [46].

Moreover, conformational changes of the mobile flap determine accessibility to the active site of JBU $[37,47,48]$. The flap also contains a reactive cysteine residue Cys592, and the proximity of the sulfide group of this residue to the $\mathrm{Ni}$ active sites may inhibit urease function by forming thiol blockages [37] (Fig. 2d). The flexible flap loses mobility resulting from modification of this residue and impedes catalytic reaction [46].

The 3D structure of urease is shown in Fig. 2a, highlighting the positions of the surface active groups (namely lysine, aspartic acid and glutamic acid) and Fig. $2 \mathrm{~b}$ in ribbon form displaying the hindered active sites respectively. Because access to the active site is blocked, the inherent structure of free urease poses a hurdle for its immobilisation. To address this challenge, we adopt a new approach, as presented in this work, i.e. CLEL technology. We exploit the low-temperature dehydration afforded by lyophilisation to minimize material loss, circumventing a problem arising from crash precipitation.

To enable both aggregation and cross-linking with the additional lysine residues, we used bovine serum albumin (BSA) as a co-aggregant [49-51]. As a support material, BSA provides additional reactive functional groups (Lys) in their structure so as to perform a reaction between the enzyme and support and facilitate the cross-linking of them [52]. A biopolymer of natural origin and biocompatibility, BSA is broadly available and relatively easy to regenerate. The immobilization cost is reduced to the fact that in general it is a by-product of various industries [52]. Since the aim of this work is to produce catalytically active immobilized-urease, the effect of BSA addition on the overall cost has been undervalued. However, one should consider the cost of the support as there may be an increase in the final cost of the product in the case of a mass production [2].

Another key step in our methodology is the use of dextran polyaldehyde (DPA) as the cross-linker. Although glutaraldehyde (GA) is a commonly used cross-linker, its low molecular weight may in fact facilitate undesirable binding with the Lys residues present in the active sites of many enzymes [26,53,54]. Furthermore, an alkaline $\mathrm{pH}$ of 9.2 in the DPA cross-linker solution additionally lowers the inhibition effect of phosphate buffers, resulting in increase of catalytic activity [55,56].

\section{Experimental}

\subsection{Materials}

\subsubsection{Chemical reagents and proteins}

Jack bean urease (EC 3.5.1.5) was obtained from Sigma-Aldrich (Urease from Canavalia ensiformis (Jack bean) (UniProtKB - P07374), Type IX, powder, 50,000-100,000 units/g solid) (a sub-unit molecular weight: $\sim 90,770$ and is composed of six sub-units with total molecular weight: 544,620). Bovine serum albumin (UniProtKB - P02769) was obtained from Sigma-Aldrich (Heat shock fraction, $\mathrm{pH} 7, \geq 98 \%$ ). Glutaraldehyde, 25\% aqueous solution and ninhydrin GR for analysis were obtained from Merck. Urea was purchased from MP Biomedicals, LLC. Ammonium sulfate was from Panreac Quimica S.A.U. Sodium borohydride was obtained from Acros. Ammonium carbonate was obtained from VWR. Other reagents and solvents used were analytical or high performance liquid chromatography (HPLC) grade. All substances were directly withdrawn from their original stock and used without pretreatment or further purification. 
a

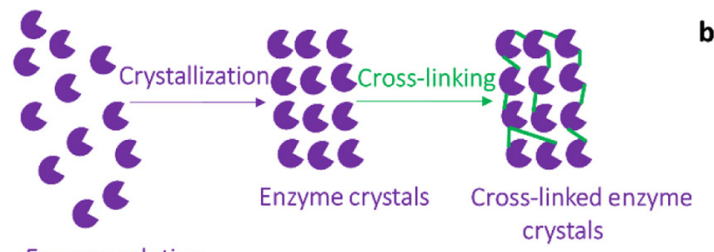

b

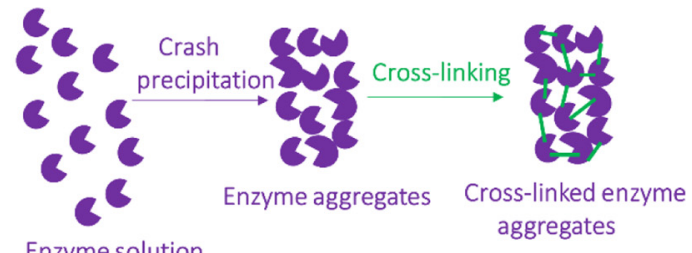

Enzyme solution

Enzyme solution

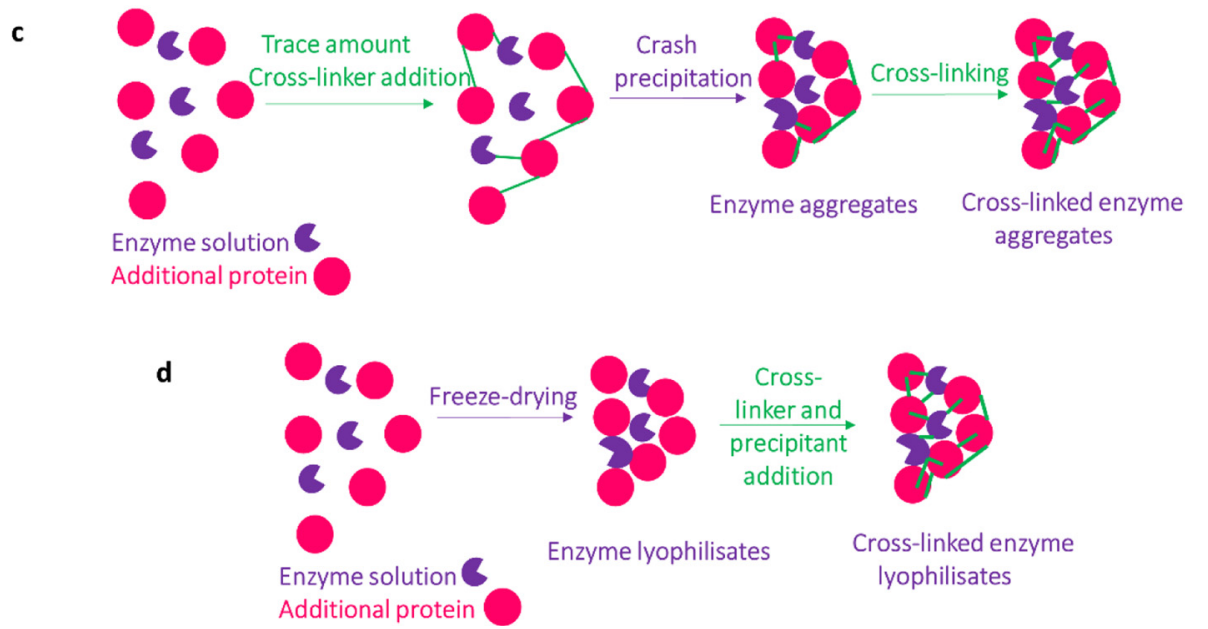

Fig. 1. Illustration of a - CLEC formation, b - CLEA formation, $c$ - CLAS formation and d - CLEL formation.

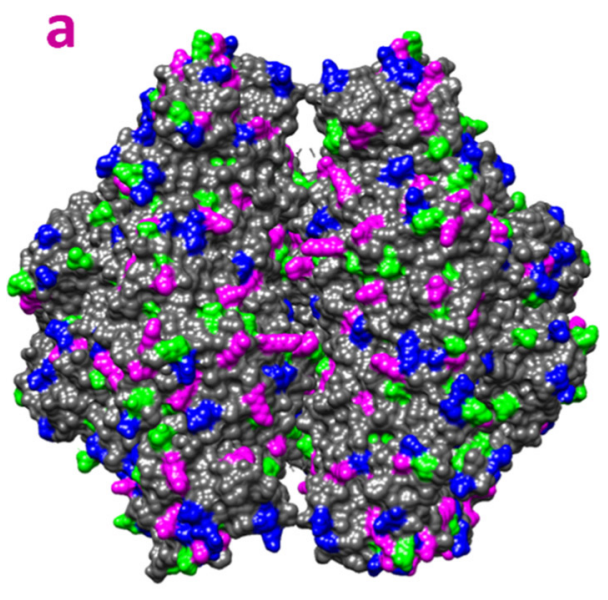

C

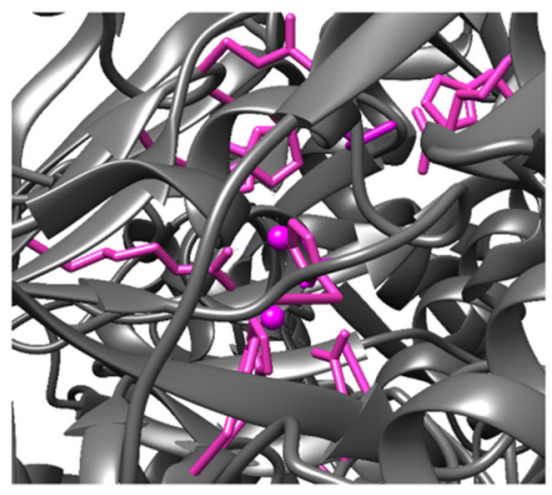

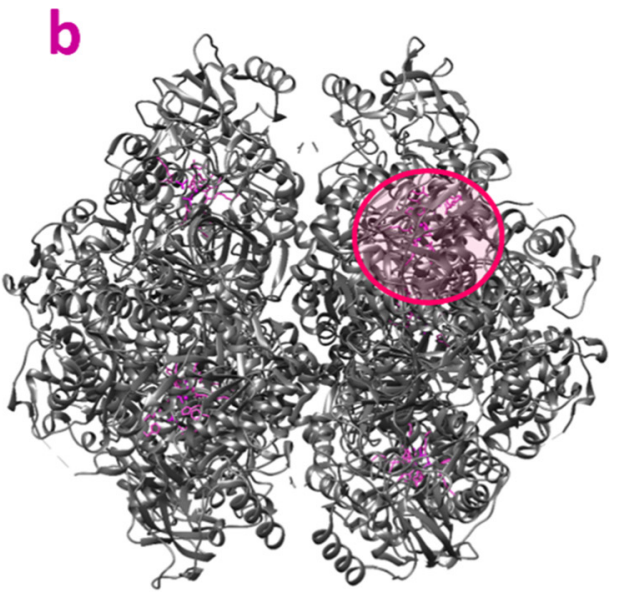

d

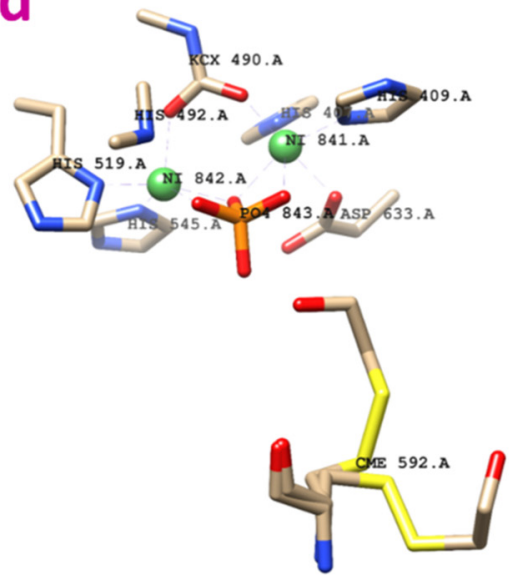

Fig. 2. a - 3D structure of JBU in hydrophobicity surface form displaying the surface active groups (Lys: magenta, Glu: blue, Asp: green) $b-3 D$ structure of JBU in ribbon form (active sites are represented in colour magenta). Active site of one subunit has been assigned with a circle. $\mathrm{c}$ - Expanded view of the active site of one subunit $\mathrm{c}-3 \mathrm{D}$ visualization of active site of JBU (KCX 490.A: carbamylated lysine, CME 592.A: cysteine, green: nickel, red: oxygen, blue: nitrogen, orange: phosphorus, white: carbon). All structural figures were generated using USCF-Chimera. The 3D structure of JBU was obtained from Protein Data Bank (PDB) with the PDB code 3LA4 (For interpretation of the references to colour in this figure legend, the reader is referred to the web version of this article). 


\subsubsection{Dextran polyaldehyde preparation}

DPA was synthesized in-house according to the following procedure [54], [57]: $1.65 \mathrm{~g}$ of dextran was dissolved in $80 \mathrm{~mL}$ of water, and $3.85 \mathrm{~g}$ of sodium metaperiodate were added. The resulting solution was stirred at room temperature for $90 \mathrm{~min}$. Subsequently, the solution was dialysed five times, using a MW cut-off of $10 \mathrm{kDa}$ against $5 \mathrm{~L}$ of water each time, at room temperature for $2 \mathrm{~h}$ and under continuous stirring. The final volume of DPA was $87 \mathrm{~mL}$.

In this work, commercial GA stocks ( $25 \mathrm{wt} \%, \mathrm{pH} 5)$ were directly used without $\mathrm{pH}$ adjustment. Water-diluted stocks (12.5 wt $\%$, adjusted to $\mathrm{pH} 9.2$ using $0.1 \mathrm{M}$ sodium carbonate buffer) were also used.

\subsection{Methods}

\subsubsection{Urease CLEL synthesis}

The starting solution was prepared with urease powder $(20 \mathrm{mg} / \mathrm{mL})$ and albumin $(0-200 \mathrm{mg} / \mathrm{mL})$ dissolved in phosphate buffer $(100 \mathrm{mM}$, $\left.\mathrm{pH} 7.4,4{ }^{\circ} \mathrm{C}\right)$. The solution was transferred into $2 \mathrm{~mL}$ capacity Eppendorf tubes, and the tube rack was immersed-i.e., flash frozen in liquid nitrogen-followed by lyophilisation $(0.02-0.04 \mathrm{mbar}, 24 \mathrm{~h})$ in a laboratory scale freeze-dryer (Christ, ALPHA 1-2 LD plus). The lyophilisates formed were dropped into a mixture of cross-linker (aqueous pH 5 GA, pH 9.2 GA, pH 4.5 DPA or pH 9.2 DPA solutions) and precipitant ( $4 \mathrm{M}$ ammonium sulfate), with variable cross-linker concentration. All reactions were conducted at $4{ }^{\circ} \mathrm{C}(20 \mathrm{~h}, 300 \mathrm{rpm})$. The cross-linked material was recovered as a pellet following centrifugation (5 min, $10 \mathrm{krpm}$ ). The pellet was treated with a freshly made aqueous

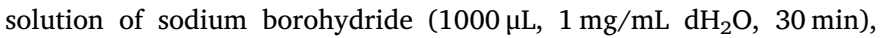
centrifuged (10 krpm, $5 \mathrm{~min}$ ), and twice reconstituted (1000 $\mathrm{L}$, RT, $5 \mathrm{~min}$ ) and centrifuged (10 krpm, $5 \mathrm{~min}$ ) in distilled water to remove traces of reagent. The wet pellet was dried under vacuum (RT, $12 \mathrm{~h}$ ) in a laboratory scale freeze-dryer (Christ, ALPHA 1-2 LD plus).

The cross-linkers, GA and DPA, were used in 3 different concentrations ( $\mathrm{mL}$ per $\mathrm{mg}$ urease), as summarized in Table 1. Briefly, Protocol 1 was the minimum concentration for both GA and DPA. Protocol 2 was a double concentration (e.g., $2 \mathrm{x}$ ) of Protocol 1, and Protocol 3 was a quadruple (e.g., 4x) concentration of Protocol 1.

\subsubsection{Residual activity}

GA cross-linked urease-CLEL, DPA cross-linked urease-CLEL, and native urease (free enzyme) were reacted in a solution of phosphate buffer (100 mM, pH 7.4) and 0.5 M urea for each cycle (30 min, room temperature). After each cycle, the mixture was centrifuged, and after removing the aliquots, a new buffer and urea solution were added to the recycled urease-CLEL. After 10 cycles, catalytic activity assay (Section 2.2.5) was applied to the dried sample.

\subsubsection{Storage stability}

A catalytic activity assay protocol (Section 2.2.5) was applied to the GA cross-linked urease-CLEL and DPA cross-linked urease-CLEL samples, which have been held at $4{ }^{\circ} \mathrm{C}$ for 5 weeks; and the shelf-life of the samples was determined.

\subsubsection{Thermal stability}

GA cross-linked urease-CLEL, DPA cross-linked urease-CLEL and free enzyme were exposed to a solution of phosphate buffer $(100 \mathrm{mM}$, $\mathrm{pH} 7.4)$ and $0.5 \mathrm{M}$ urea for $1 \mathrm{~h}\left(25-85^{\circ} \mathrm{C}\right)$. Thermal stability was

Table 1

Cross-linker concentrations in 3 different protocols $(\mathrm{x}=\mathrm{mL} / \mathrm{mg}$ urease).

\begin{tabular}{llll}
\hline & $\begin{array}{l}\text { Protocol 1 Conc. } \\
\mathrm{x}\end{array}$ & $\begin{array}{l}\text { Protocol 2 Conc. } \\
2 \mathrm{x}\end{array}$ & $\begin{array}{l}\text { Protocol 3 Conc. } \\
4 \mathrm{x}\end{array}$ \\
\hline Glutaraldehyde & $1.5 \times 10^{-4}$ & $3 \times 10^{-4}$ & $6 \times 10^{-4}$ \\
Dextran polyaldehyde & $7.5 \times 10^{-4}$ & $1.5 \times 10^{-3}$ & $3 \times 10^{-3}$ \\
\hline
\end{tabular}

quantified by using the catalytic activity assay protocol (Section 2.2.5) after centrifugation and drying.

\subsubsection{Characterization of urease CLEL}

2.2.5.1. Scanning electron microscopy (SEM). To analyse the morphology of the particles produced, a conductive coating was deposited onto the CLEL powder (Cressington Sputter Au/Pd Coater) to an approximate thickness of 2-3 $\mathrm{nm}$. Secondary electron images were recorded using a $2 \mathrm{keV}$ beam in a Leo Supra $55 \mathrm{~V}$ P SEM.

2.2.5.2. Determination of aggregation. Reactions were conducted in preweighed $50 \mathrm{~mL}$ falcon tubes. The falcons were weighed again after lyophilisation and cross-linking. The aggregation yield was calculated according to the following equation:

Aggregation yield $(\%)=\frac{\mathrm{W}_{\text {clel }}}{\mathrm{W}_{\mathrm{l}}} \times 100$

$\mathrm{W}_{\text {clel }}$ is the dry weight of urease CLEL, and $\mathrm{W}_{1}$ is the dry weight of the lyophilisate.

2.2.5.3. ATR-FTIR molecular structure analysis. Attenuated totalreflectance Fourier-transform infrared spectroscopy (ATR-FTIR) was used to directly monitor changes of dipole moment in the amide groups as a function of the cross-linker amount. Using a Thermo Scientific ${ }^{\text {TM }}$ Nicolet iS10 FT-IR spectrometer, 34 consecutive scans were acquired per sample, and the averaged result was baseline-corrected.

2.2.5.4. Urease catalytic activity assay protocol. For determining the urease activity, a colorimetric assay based on ninhydrin colour-yield was applied to the samples to detect the free amines. A $3 \mathrm{~h}$ activity assay reaction was conducted at room temperature for a $2 \mathrm{mg} / \mathrm{mL}$ solution of urease-CLEL and isopropanolic ninhydrin ( $50 \mu \mathrm{L} ; 1 \mathrm{wt} \%)$. The product was used as the reagent for the supernatant of the samples $(50 \mu \mathrm{L})$. After $1 \mathrm{~h}$ of incubation at $70^{\circ} \mathrm{C}$, UV-vis spectrophotometric analyses at $\lambda_{\text {ex }}=595 \mathrm{~nm}$ were performed for all samples, using a BioRad Model 680 Microplate (ELISA) Reader. The relative activity (\%) was compared, by assessing the urease mass fraction within each CLEL against an equal mass of free enzyme. The free enzyme was arbitrarily assigned a value of $100 \%$.

\subsection{Statistical analysis}

All in vitro results represent 4 independent experiments. All numerical data are shown as mean \pm SD (standard deviation), calculated by the following formula, where $n=$ the number of data points, $x_{i}=$ each of the values of the data and $\bar{x}=$ the mean of $x_{i}$.

$S D=\sqrt{\frac{\sum_{i=1}^{n}\left(x_{i}-\bar{x}\right)^{2}}{n-1}}$

$P$ values were determined by two-tailed Student's $t$-tests. The asterisk indicates statistical significance when each activity was compared to that of free enzyme $(* * * * p<0.0001$, *** p $<0.001, * * \mathrm{p}<0.01$, * $\mathrm{p}<0.05$, ns (not significant) $\mathrm{p}>0.05$ ).

\section{Results}

To evaluate the morphology of the urease-CLELs, we analysed by SEM imaging the samples of urease:albumin with a weight ratio of 1:5; these were cross-linked with alkaline $\mathrm{pH}$ cross-linkers ( $\mathrm{pH} 9.2$ both for GA and DPA; cross-linker concentration 4-fold increase). The results are summarized in Fig. 3 for the free enzyme and the urease-CLELs at two different magnifications. The urease-CLELs have more uniform shapes when compared to free enzyme, and the surface area has increased after cross-linking. According to previous literature, Schoevaart et al. have reported that CLEAs have either a typical ball-like appearance (type 1) 


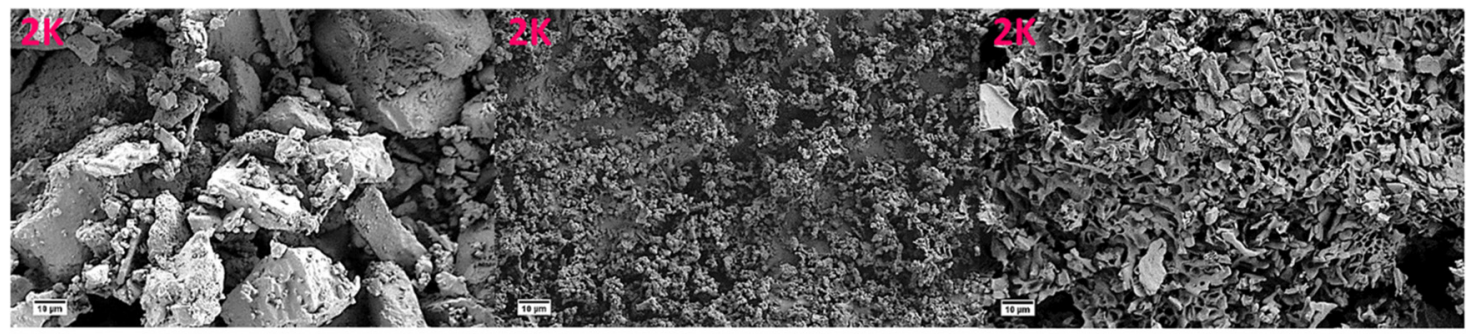

a - Free urease

b - CLEL w/ DPA

c-CLEL w/ Glutaraldehyde

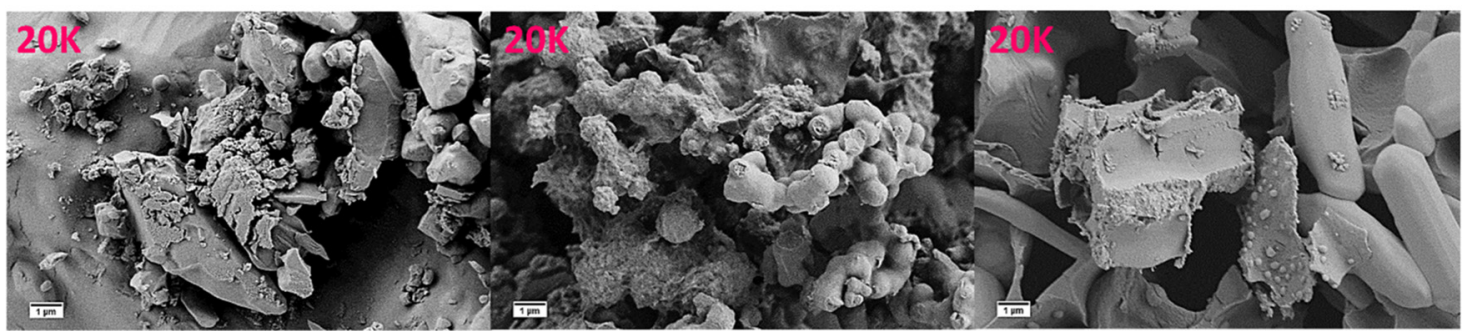

Fig. 3. SEM images at $2 \mathrm{~K}$ and $20 \mathrm{~K}$ magnification of a - free urease; and cross-linked urease CLEL with b - dextran polyaldehyde, c - glutaraldehyde.

or a less-defined cluster form (type 2) [27]. The SEM imaging revealed that DPA produces $c a .1 \mu \mathrm{m}$-diameter, spheroidal powder particles, whereas GA yields aggregates of nanometer sized spheres.

Fig. 4 summarizes the quantitative analysis of the aggregation yields of CLELs cross-linked viaGA and DPA (pH 5). In both cases, the yields range between $96-100 \%$, due to the minimal material loss involved in lyophilisation, in contrast to the aggregation step in the water surroundings of conventional precipitation. As shown in Fig. 4, the standard deviation values are negligible.

To validate successful cross-linking of the urease-CLELs, we performed ATR-FTIR, monitoring changes in dipole moment of the amide bond and other spectral regions as a function of the degree of crosslinking. The spectra in Fig. 5 correspond to samples with increasing amounts of cross-linking agent (Protocols 1-2-3). They reveal the appearance of the amide I (i.e., $\mathrm{C}=\mathrm{O}$ stretching, $1650 \mathrm{~cm}^{-1}$ ) and II (i.e., $\mathrm{N}$ $\mathrm{H}$ bending, $1540 \mathrm{~cm}^{-1)}$ bands, which are not present in the free enzyme. Because they indicate coupling of amino groups, from both BSA and the Lys group of urease, with the carbonyl group of the cross-linker to form amides, the associated vibration resonances in the FTIR spectra thus indicate that the urease-CLELs are cross-linked. Additional supporting evidence is revealed by the vibration band corresponding to alkane $\mathrm{C}-\mathrm{H}$ bending $\left(1450 \mathrm{~cm}^{-1}\right)$ and the $\mathrm{C}-\mathrm{O}$ stretching resonance $\left(1100 \mathrm{~cm}^{-1}\right)$, both of which increased with cross-linker concentration (Fig. 5).

To characterise the catalytic properties of urease-CLELs for potential application, we evaluated the effect of BSA amount (Fig. 6a), pH (Fig. 6b), and cross-linker amount and type (Fig. 6c) viathe relative

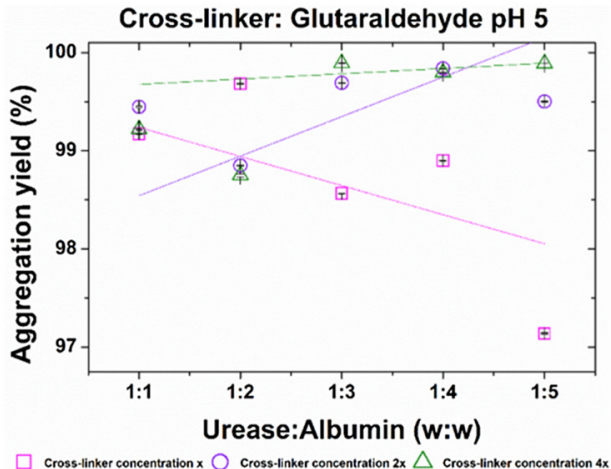

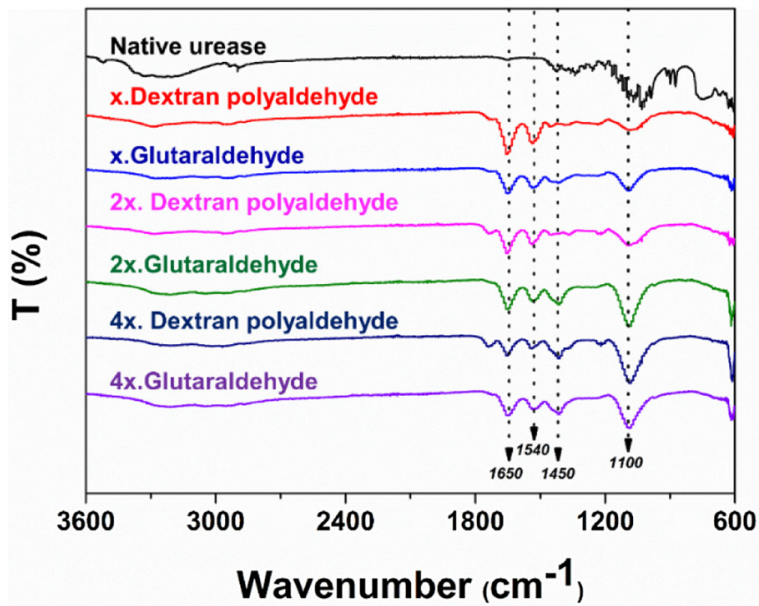

Fig. 5. FT-IR spectrum of native urease (free enzyme) vsurease-CLEL for dextran polyaldehyde and glutaraldehyde with increasing cross-linker concentration.

dependence of urease-CLEL catalytic activity on the urease:albumin (w:w) ratio. The urease:albumin weight ratios investigated were 1:2, 1:3, 1:4 and 1:5, where the cross-linker $\mathrm{pH}$ was alkaline ( $\mathrm{pH} 9.2$ both for GA and DPA), and the cross-linker concentration was 4 times that of

b

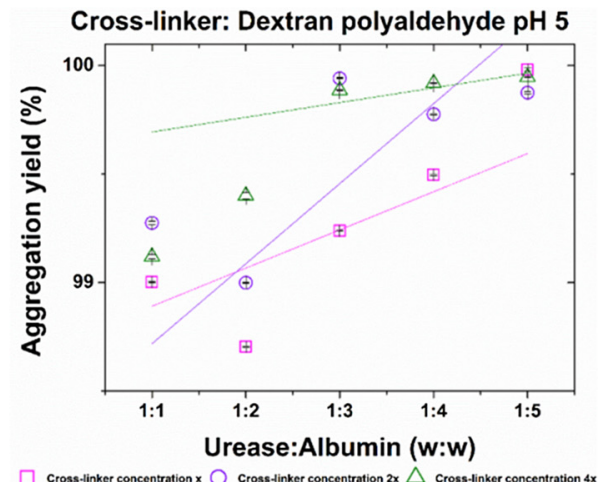

Fig. 4. Aggregation yields (\%) of a - glutaraldehyde b - dextran polyaldehyde cross-linked samples at 3 different concentrations ( $\mathrm{pH}$ 5). Data represents the mean results $\pm \mathrm{SD}, \mathrm{n}=3$. 

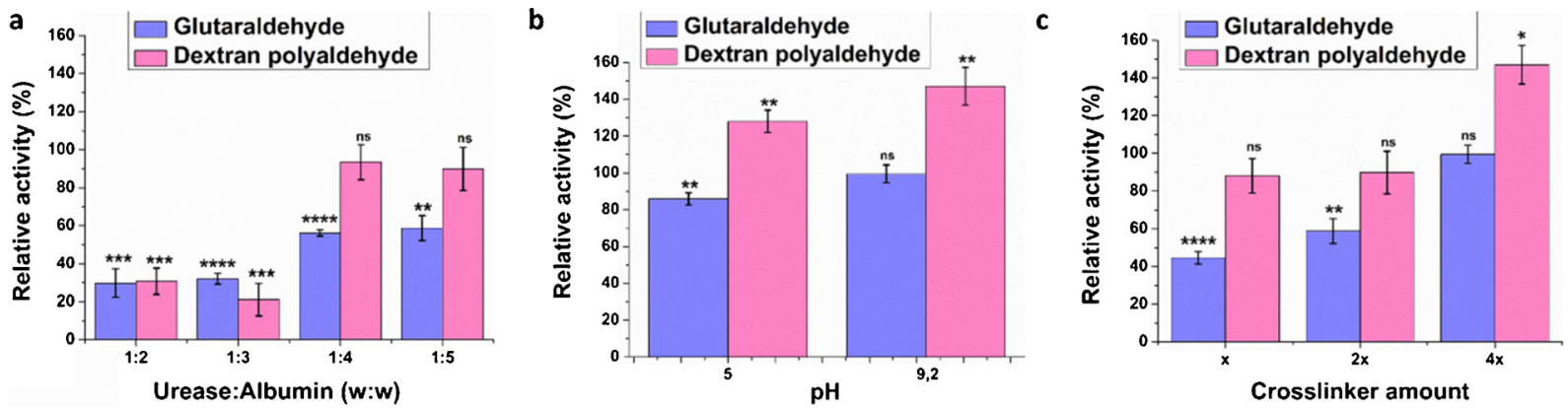

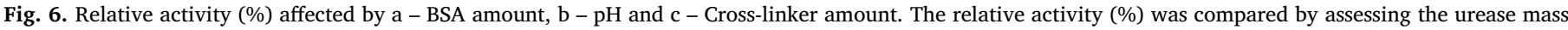

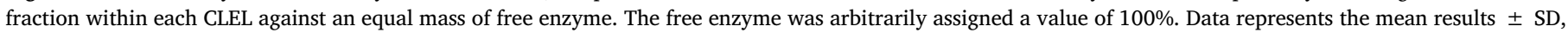
$\mathrm{n}=4\left(* * * * \mathrm{p}<0.0001,{ }^{* * *} \mathrm{p}<0.001,{ }^{* *} \mathrm{p}<0.01,{ }^{*} \mathrm{p}<0.05\right.$, ns (not significant) $\mathrm{p}>0.05$ ).
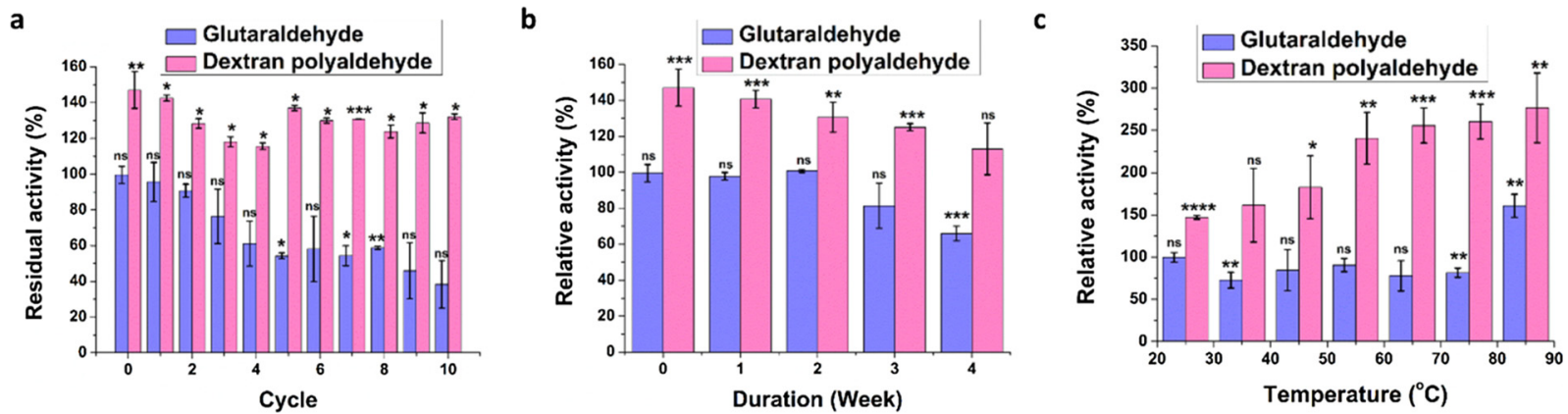

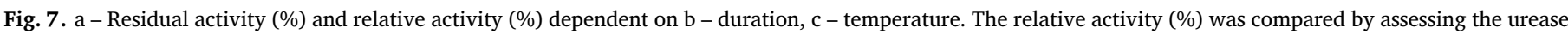

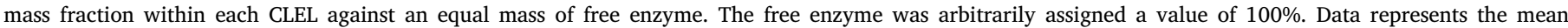
results $\pm \mathrm{SD}, \mathrm{n}=4\left({ }^{* * * *} \mathrm{p}<0.0001,{ }^{* *} \mathrm{p}<0.001,{ }^{* *} \mathrm{p}<0.01,{ }^{*} \mathrm{p}<0.05\right.$, ns (not significant) $\mathrm{p}>0.05$ ).

\section{Protocol 1.}

We also analysed the residual activity, storage and thermal stabilities for these urease-CLEL samples, with the results summarized in Fig. 7. The cross-linker concentrations were 4 times of those of the sample, Protocol 1.

\section{Discussion}

\subsection{Urease CLEL synthesis}

To produce urease-CLELs, we have developed a protocol involving the introduction of lyophilisation, inducing co-aggregation with BSA, inducing cross-linking with glutaraldehyde and dextran poly-aldehyde, and tuning $\mathrm{pH}$. We have systematically investigated the effect of each process parameter on the catalytic activity of urease-CLELs. Each of the urease-CLELs produced consistently showed higher activity than free urease, suggesting that each processing step did not adversely change the conformation and mobility of the active site flap of urease so that the mobile flap is able to open and close ensuring the continuity of the catalytic cycle.

Initial attempts to cross-link urease viathe conventional CLEA method produced insufficient yields, due to poor protein precipitation and uncontrolled cross-linking of the precipitant. The poor cross-linking was attributed to a high tendency for relatively inert intra-molecular ammonium carboxylate bridges to form, as well as the poor availability of a low density of attachment points (Fig. 2a), as shown in the 3D structure of urease.

In addition, the particular conformation of surface groups in the urease structure leads to challenges for both precipitation and nonspecific covalent cross-linking steps in the conventional CLEA technique. The structure can be understood by considering images obtained from the Protein Data Bank (PDB) shown in Fig. 2a, where the residues Lys (lysine) are indicated in magenta colour, Glu (glutamic acid) in blue, and Asp (aspartic acid) in green. The surface carboxyl and amino groups, while present in apparent abundance, have a strong tendency to form relatively inert, intra-molecular ammonium carboxylate bridges-i.e., "salt-bridges", while offering few prominent attachment points. The relatively low solubility of the enzyme underscores its weakly hydrophilic or hydrophobic character, rendering it difficult to precipitate viaa "salting out" approach or use of an anti-solvent. The low cross-linking efficiency may also be attributed to the conformationally impaired reactivity of the target functional residues [40].

Urease immobilization is a challenging process, due to the restricted exposure of active sites, as shown in Fig. 2a. Even though there is a significant number of Lys groups present on the surface of urease, both aggregation and cross-linking still proved difficult. Urease is a moderately water soluble protein (up to $50 \mathrm{mg} / \mathrm{mL}$ ). As evident from the surface structure, the majority of Lys residues are in close proximity to a carboxylic acid, which it would favour over a foreign cross-linking molecule bearing a similar carboxylic acid group (see for example, Fig. 8a). Because urease is neither strongly hydrophilic nor hydrophobic, precipitation is inefficient through the gradual removal of the solvating water. Furthermore, the challenge for cross-linking may also be attributed similarly to the reduced availability of surface amine residues, due to intra-molecular salt-bridge interactions. These problems could be surmounted by lyophilisation-i.e. by-passing the liquid phase when dehydrating the frozen product.

Another key step in our methodology is the use of BSA as a carrier/ protector [49]. When there is a low density of surface reactive amino groups or they are not available as in the case of urease, performing immobilisation and obtaining a final solid biocatalyst is challenging [58]. BSA has a high surface density of amino groups, which offer more attachment points for cross-linking, as well as for suppressing the formation of carboxylate bridges, thereby protecting the active Ni sites of urease [49,51]. Co-precipitation with albumin has already been reported, serving the aim to both improve aggregation and provide additional Lys residues [31], to facilitate the yield of inter-protein crosslinking. It has also been shown to improve the activity and thermal 

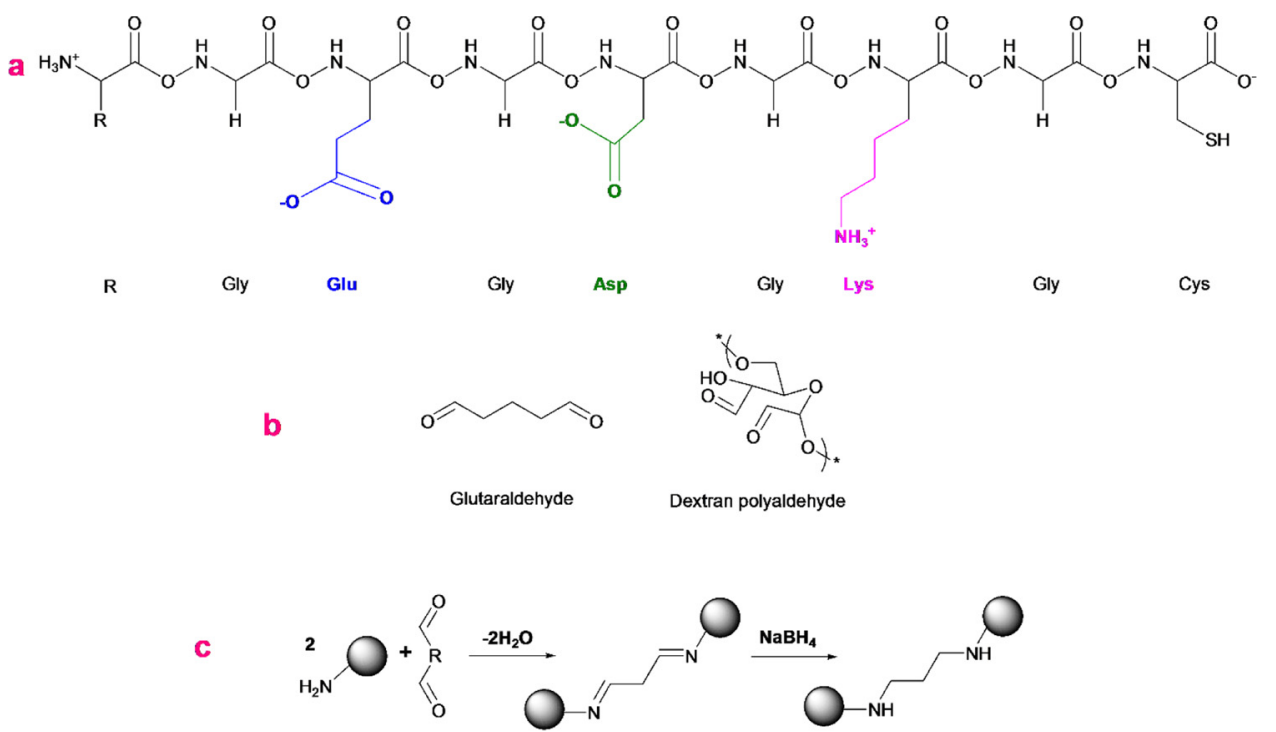

Fig. 8. a - Common amino acid functional groups targeted for bioconjugation $\mathrm{b}$ - Chemical structure of the cross-linkers $\mathrm{c}$ - Reductive amination reaction of aldehyde cross-linkers.

stability [59], in addition to enhanced storage stability and reusability profiles, in a recent study [60]. In fact, two of the precedents for urease CLEA in the literature reveal the potential of BSA as a co-aggregant $[50,51]$.

Our process also required covalent cross-linking, which has already been achieved viaconventional techniques, that relied on the reaction of protein side chains or terminal functional groups as the means for obtaining insoluble cross-linked aggregates. These non-specific techniques primarily target the surface-exposed, and thus chemically reactive, amino residues. GA is the most commonly used reagent for immobilizing enzymes, by reacting with the primary amino groups of the proteins [58] and exploiting the Lys groups on the surface to form aggregates [7]. In the cases of proteins with less abundant surface lysine content, DPA has shown higher yield. It also provides milder reaction conditions, reducing toxicity risk, and is therefore preferred in many biomedical applications. Yet another important rationale mentioned in literature is use of this cross-linker as an alternative to low molecular weight GA, to prevent the modification of Lys side residues that are present in the active sites of many enzymes [26,53,54]. Due to its small size, GA can access and bond with amino groups at the active site, causing a decrease in the catalytic activity. By contrast, the bulkier DPA is not able to penetrate the protein and disable the amino groups by cross-linking reaction [61]. There are several examples of employing DPA as the cross-linker of CLEA in industrial production [26,54,62]. We demonstrate the successful cross-linking behaviour by both molecules in Fig. 8b. The reductive amination reaction between the aldehyde cross-linker and the Lys group of the enzyme is shown in Fig. 8c. If further chemical modification of the enzyme is not intended, the reactivity of the groups may be eliminated viasodium borohydride reduction [7].

Consequently, we have implemented variations on established methods to prepare urease CLEAs to bypass such obstacles, and the most promising results were obtained viathe i) CLAS method, and ii) CLEL method, both of which were achieved by co-aggregation with BSA. In the first method, urease and BSA, which facilitated precipitation, were initially allowed to cross-link in aqueous solution, when we introduced traces of GA (see Supplementary Material). By way of this unconventional approach, we achieved the co-aggregation of a ureaseBSA derivative, which we then cross-linked vianormal CLEA methods. Because the relative catalytic activity obtained from this method was not satisfactory (see Fig. S1), we developed the second method (CLEL) to by-pass problems arising from the structural anomalies of urease.
In the CLEL method, we lyophilised urease together with BSA (as the carrier protein), and the resulting powder was rapidly dispersed in aqueous solutions containing different cross-linking agents, GA or DPA. The presumed advantage of this second method was that lyophilisation enables a liquid-to-powder transformation by sublimation, bypassing any opportunity for material loss. Hence, by means of either method, we obtained urease in an insoluble powder form, as a co-aggregate with albumin. These results have a broader significance by offering a general alternative for cross-linking proteins that cannot precipitate efficiently in conventional crash-precipitation-i.e., in anti-solvent and salting-out methods.

\subsection{The effect of lyophilisation}

Because urease-CLEAs prepared by CLAS showed poor reactivity (Fig. S1), we considered freeze-drying (lyophilisation) to eliminate water molecules in the samples by sublimation and desorption. Rupley et al. explained that a minimum amount of water is necessary to make the enzyme active [63]. The hydration of a macromolecule requires a very large amount of free energy, which eventually creates a large effect on enzyme properties and active site structure. If there are numerous surrounding water molecules, inter-domain water bridges break randomly, resulting in fluctuations and effecting the domains and the substrate, that are responsible for the active cleft [63]. Accordingly, when the environment is lacking in water molecules, the amino acid residues are able to interact with each other and the flexibility, i.e., ability to open and close, of the enzyme molecule, which is important for its catalytic activity, is retained in the dry state. The result is higher catalytic activity [32], even at elevated temperatures [64]. The high aggregation yields shown in Fig. 4 confirmed our hypothesis that lyophilisation would enable us to circumvent the cross-linking and aggregation problems in immobilizing urease in CLELs.

Because the absolute activity increased with the amount of BSA present (Fig. 6), we attribute the increase in apparent bioactivity to improved access to the $\mathrm{Ni}$ active sites [65-67], due to the increasing amino group density with BSA content. With a high surface density of amino groups, BSA is well suited for cross-linking to the surface amino groups of urease, i.e. the Lys, consequently suppressing salt-bridge formation near the $\mathrm{Ni}$ active sites on urease. During co-aggregation with urease, BSA behaves as a proteic feeder with the free amino groups on the surface. Because there are enough surface Lys residues on the surface of the protein $[68,69]$, these groups react with the cross-linker, 
in which case the active site of urease is protected [49,51].

\section{3. $p H$ dependence}

When the alkaline ( $\mathrm{pH}$ 9.2) cross-linker was preferred to the acidic one for the cross-linking step, we observed a significant increase in relative activity (Fig. 6b), consistent with the known stabilisation of a Schiff base-i.e., amino group-reaction in increased $\mathrm{pH}$ [70]. Consequently, cross-linking density increased; urease was better stabilised, and active site access on the urease surface better preserved. Phosphate buffers are known to serve as a weak inhibitor for urease, when the $\mathrm{pH}$ is neutral, viabridging the two $\mathrm{Ni}$ ions [71,72]. For the urease CLELs exposed to $\mathrm{pH}<6.5$, the $\mathrm{H}_{2} \mathrm{PO}_{4}{ }^{-}$ion was protonated and could access the active site, while for a $\mathrm{pH}>6.5$, the ion was repulsed from the active site, lowering the inhibition effect and allowing higher reactivity $[55,56]$. Moreover, depending on the immobilization $\mathrm{pH}$, some conformational changes may occur through the high number of enzymesupport linkages [73].

\subsection{The effect of cross-linker amount and type}

The samples cross-linked in an alkaline $\mathrm{pH}(\mathrm{pH} 9.2$ both for GA and DPA) showed an increase in activity with increasing cross-linker concentration (Fig. 6c). Because GA is a smaller cross-linker, it was able to penetrate better into the urease-BSA aggregate to the active site and block catalytic activity. By contrast, DPA, having a bulkier molecular structure, was less able to react with the Lys residues in the active cleft [26], yielding higher relative catalytic activity.

The presence of amide I and II bond vibration modes (Fig. 5) also confirmed cross-linking in the urease-CLELs. Combined with the dependence of activity on cross-linker amount, our results indicate that cross-linking to the Cys592 residue of urease may provide flexibility to the mobile flap. Therefore, it ensures that the substrate is able to enter the active site (open), the reaction occurs (closed), and the products leave (open), resulting in the observed increase in catalytic activity [74].

\subsection{Residual activity}

Because CLEAs are recyclable [29,75], our urease-CLELs may also have attractive potential for greener, lower-cost synthesis. Thus to address their recyclability, we also evaluated the ease of recovering the immobilized enzymes from the reaction solution. After 10 reaction-recovery cycles, the residual activity showed a $10 \%$ decrease from the initial value (Fig. 7a). Such a low decrease underscored the superior recyclability of these urease-CLELs, when compared to the performance of CLEAs, whose activity decreased by $20 \%$ after only 6 recovery cycles [51].

\subsection{Storage stability}

We monitored the storage stability of the urease-CLELs over 5 weeks, by measuring the residual urease activity (Fig. $7 \mathrm{~b}$ ) at $4{ }^{\circ} \mathrm{C}$. The urease-CLELs had largely retained their catalytic activities, showing superior storage stability to immobilized urease in CLEAs, which retained $60 \%$ of the initial activity after 10 days storage at $4{ }^{\circ} \mathrm{C}$ [51].

\subsection{Thermal stability}

Another important reason for immobilizing enzymes is that native ones become less stable when exposed to elevated temperatures. We have seen that when the temperature is increased from 25 to $85^{\circ} \mathrm{C}$, the relative catalytic activity increased by $50 \%$ for GA cross-linked ureaseCLEL and by $100 \%$ for DPA cross-linked urease-CLEL. In contrast, immobilized urease in other forms showed a decrease in the activity after $70{ }^{\circ} \mathrm{C}[76]$. These results confirm the stable catalytic activity of urease-
CLELs under standard thermal conditions demanded for biological catalysts (Fig. 7c).

\section{Conclusions}

We have demonstrated a simple method for immobilizing urease of high catalytic activity by producing urease-CLELs. Although lyophilisation stabilizes the JBU structure, freeze-drying performed on JBU without BSA resulted in poorer catalytic activity. By co-aggregating JBU first with BSA, an increase occurred in the concentration of surface Lys residues, which coupled to the carbonyl group of 2 cross-linking agents, GA and DPA and produced a high aggregation yield. The increased catalytic activity indicates that active site access was preserved in the stabilized enzyme. The higher catalytic activity achieved by the bulkier DPA molecules suggested more successful avoidance of blocking active-site access. $\mathrm{pH}$ studies revealed that the phosphate buffer inhibited active site access, which was overcome by increasing alkalinity of the cross-linker solution. As a result of all these processes, the mobile flap of the urease active cleft remains free to open and close unimpeded, as required for the catalytic cycle. Our new process offers a general alternative for cross-linking proteins that are not precipitated efficiently by conventional crash-precipitation-i.e., using anti-solvent and salting-out methods. Furthermore, we demonstrate that, urease CLELs are thermally stable with a long lifetime, as well as being recyclable-i.e., possessing characteristics attractive for greener industrial processing of important commodity compounds.

\section{Protein data bank accession numbers}

The 3D structures of urease were obtained from the Protein Data Bank (PDB) using Chimera v. 1.13. Urease Protein Data Bank can be accessed through the number 3LA4.

\section{Accession codes}

Jack Bean Urease (EC 3.5.1.5) (UniProtKB P07374)

Bovine Serum Albumin (UniProtKB - P02769)

\section{Declaration of competing interest}

The authors have no conflicts of interest to declare.

\section{Acknowledgments}

This project is financially supported by Tubitak (The Scientific and Technological Research Council of Turkey) with the grant number 111M680. T.A. gratefully acknowledges Mehmet Ali Gulgun, Omid Mohammad Moradi, Fevzi Cakmak Cebeci and Serkan Unal for their support on the paper and Senem Avaz Seven and Asli Yenenler for the help on the 3D structures.

\section{Appendix A. Supplementary data}

Supplementary material related to this article can be found, in the online version, at doi:https://doi.org/10.1016/j.enzmictec.2019. 109390.

\section{References}

[1] D. de Andrades, N.G. Graebin, M.K. Kadowaki, M.A.Z. Ayub, R. FernandezLafuente, R.C. Rodrigues, Immobilization and stabilization of different $\beta$-glucosidases using the glutaraldehyde chemistry: optimal protocol depends on the enzyme, Int. J. Biol. Macromol. 129 (2019) 672-678.

[2] C. Garcia-Galan, Á. Berenguer-Murcia, R. Fernandez-Lafuente, R.C. Rodrigues, Potential of different enzyme immobilization strategies to improve enzyme performance, Adv. Synth. Catal. 353 (16) (2011) 2885-2904.

[3] A. Schmid, J.S. Dordick, B. Hauer, A. Kiener, M. Wubbolts, B. Witholt, Industria 
biocatalysis today and tomorrow, Nature 409 (6817) (2001) 258-268.

4] D.H. Zhang, L.X. Yuwen, Y.L. Xie, W. Li, X.B. Li, Improving immobilization of lipase onto magnetic microspheres with moderate hydrophobicity/hydrophilicity, Colloids Surf. B Biointerfaces 89 (2012) 73-78.

[5] A. Ballesteros, F.J. Plou, J.L. Iborra, P.J. Halling, Stability and stabilization of biocatalysts, Prog. Biotechnol. 15 (1998) 417.

[6] R.C. Rodrigues, C. Ortiz, Á. Berenguer-Murcia, R. Torres, R. Fernández-Lafuente, Modifying enzyme activity and selectivity by immobilization, Chem. Soc. Rev. 42 (15) (2013) 6290-6307.

[7] N. Rueda, J.C.S. dos Santos, C. Ortiz, R. Torres, O. Barbosa, R.C. Rodrigues, Á. Berenguer-Murcia, R. Fernandez-Lafuente, Chemical modification in the design of immobilized enzyme biocatalysts: drawbacks and opportunities, Chem. Rec. 16 (3) (2016) 1436-1455.

[8] D.N. Tran, K.J. Balkus Jr., Perspective of recent progress in immobilization of enzymes, ACS Catal. 1 (8) (2011) 956-968.

[9] T. Jesionowski, J. Zdarta, B. Krajewska, Enzyme immobilization by adsorption: a review, Adsorption 20 (2014) 801-821.

[10] J. Guisán, Aldehyde-agarose gels as activated supports for immobilization-stabilization of enzymes, Enzyme Microb. Technol. 10 (6) (1988) 375-382.

[11] C. Mateo, O. Abian, R. Fernandez-Lafuente, J.M. Guisan, Reversible enzyme immobilization via a very strong and nondistorting ionic adsorption on supportpolyethylenimine composites, Biotechnol. Bioeng. 68 (1) (2000) 98-105.

[12] J.M. Palomo, G. Muñoz, G. Fernández-Lorente, C. Mateo, R. Fernández-Lafuente, J.M. Guisán, Interfacial adsorption of lipases on very hydrophobic support (octadecyl-sepabeads): immobilization, hyperactivation and stabilization of the open form of lipases, J. Mol. Catal. B Enzym. 19-20 (2002) 279-286.

[13] R. Torres, C. Mateo, M. Fuentes, J.M. Palomo, C. Ortiz, R. Fernandez-Lafuente, J.M. Guisan, A. Tam, M. Daminati, Reversible immobilization of invertase on Sepabeads coated with polyethyleneimine: optimization of the biocatalyst's stability, Biotechnol. Prog. 18 (6) (2002) 1221-1226.

[14] L. Cao, L. Langen, R.A. Sheldon, Immobilised enzymes: carrier-bound or carrierfree? Curr. Opin. Biotechnol. 14 (4) (2003) 387-394.

[15] A.F.S.A. Habeeb, Preparation of enzymically active, water-insoluble derivatives of trypsin, Arch. Biochem. Biophys. 119 (1967) 264-268.

[16] E.F. Jansen, A.C. Olson, Properties and enzymatic activities of papain insolubilized with glutaraldehyde, Arch. Biochem. Biophys. 129 (1) (1969) 221-227.

[17] F.A. Quiocho, F.M. Richards, Intermolecular cross linking of a protein in the crystalline state: carboxypeptidase-A, Proc. Natl. Acad. Sci. U. S. A. 52 (1964) 833-839.

[18] A.L. Margolin, M.A. Navia, Protein crystals as novel catalytic materials, Angew. Chemie Int. Ed. 40 (12) (2001) 2204-2222.

[19] G.M. Alter, D.L. Leussing, H. Neurath, B.L. Vallee, Kinetic properties of carboxypeptidase B in solutions and crystals, Biochemistry 16 (16) (1977) 3663-3668.

[20] N.L.S. Clair, M.A. Navia, Cross-linked enzyme crystals as robust biocatalysts, J. Am. Chem. Soc. 114 (18) (1992) 7314-7316.

[21] Y.F. Wang, K. Yakovlevsky, B.L. Zhang, A.L. Margolin, Cross-linked crystals of subtilisin: versatile catalyst for organic synthesis, J. Org. Chem. 62 (1997) 3488-3495.

[22] J. Lalonde, Practical catalysis with enzyme crystals, Chemtech 27 (1997) 38-45.

[23] L. Cao, F. van Rantwijk, R.A. Sheldon, Cross-linked enzyme aggregates: a simple and effective method for the immobilization of penicillin acylase, Org. Lett. 2 (10) (2000) 1361-1364.

[24] L. Cao, L.M. van Langen, F. van Rantwijk, R.A. Sheldon, Cross-linked aggregates of penicillin acylase: robust catalysts for the synthesis of $\beta$-lactam antibiotics, J. Mol. Catal. B Enzym. 11 (4) (2001) 665-670.

[25] P. López-Serrano, L. Cao, F. van Rantwijk, R.A. Sheldon, Cross-linked enzyme aggregates with enhanced activity: application to lipases, Biotechnol. Lett. 24 (16) (2002) 1379-1383.

[26] C. Mateo, J.M. Palomo, L.M. van Langen, F. van Rantwijk, R.A. Sheldon, A new, mild cross-linking methodology to prepare cross-linked enzyme aggregates, Biotechnol. Bioeng. 86 (3) (2004) 273-276.

[27] R. Schoevaart, M.W. Wolbers, M. Golubovic, M. Ottens, A.P. Kieboom, F. van Rantwijk, L.A. van der Wielen, R.A. Sheldon, Preparation, optimization, and structures of cross-linked enzyme aggregates (CLEAs), Biotechnol. Bioeng. 87 (6) (2004) 754-762.

[28] R.A. Sheldon, Cross-linked enzyme aggregates (CLEAs): stable and recyclable biocatalysts, Biochem. Soc. Trans. 35 (Pt 6) (2007) 1583-1587.

[29] R.A. Sheldon, Characteristic features and biotechnological applications of crosslinked enzyme aggregates (CLEAs), Appl. Microbiol. Biotechnol. 92 (3) (2011) 467-477.

[30] A. Taralp, Crosslinked Protein Nanocrystals, Crosslinked Protein Nanoaggregates and Method of Preparation Thereof, United States Patent, 2014

[31] R.A. Sheldon, CLEAs, combi-CLEAs and 'Smart' magnetic CLEAs: biocatalysis in a bio-based economy, Catalysts 9 (3) (2019) 261.

[32] I. Roy, M.N. Gupta, Freeze-drying of proteins: some emerging concerns, Biotechnol. Appl. Biochem. 39 (2) (2004) 165-177.

[33] J.B. Sumner, The isolation and crystallization of the enzyme urease: preliminary paper, J. Biol. Chem. 69 (1926) 435-441.

[34] N.E. Dixon, C. Gazzola, R.L. Blakeley, B. Zerner, Jack bean urease (EC 3.5.1.5), Metalloenzyme. Simple biological role for nickel, J. Am. Chem. Soc. 97 (14) (1975) 4131-4133.

[35] Y. Qin, J. Cabral, Review properties and applications of urease, Biocatal. Biotransformation 20 (1) (2002) 1-14.

[36] B. Krajewska, Ureases. II. Properties and their customizing by enzyme immobilizations: a review, J. Mol. Catal. B Enzym. 59 (1-3) (2009) 22-40.

[37] C. Follmer, Insights into the role and structure of plant ureases, Phytochemistry 69 (1) (2008) 18-28.
[38] S.V. Marchenko, I.S. Kucherenko, A.N. Hereshko, I.V. Panasiuk, O.O. Soldatkin, A.V. El'skaya, A.P. Soldatkin, Application of potentiometric biosensor based on recombinant urease for urea determination in blood serum and hemodialyzate, Sens. Actuators B Chem. 207 (2015) 981-986.

[39] L. Faye, J.S. Greenwood, M.J. Chrispeels, Urease in jack-bean (Canavalia ensiformis (L.) DC) seeds is a cytosolic protein, Planta 168 (4) (1986) 579-585.

[40] A. Balasubramanian, K. Ponnuraj, Crystal structure of the first plant urease from jack bean: 83 years of journey from its first crystal to molecular structure, J. Mol. Biol. 400 (3) (2010) 274-283.

[41] N.E. Dixon, P.W. Riddles, C. Gazzola, R.L. Blakeley, B. Zerner, Jack bean urease (EC 3.5.1.5). V. On the mechanism of action of urease on urea, formamide, acetamide, N-methylurea, and related compounds, Can. J. Biochem. 58 (12) (1980) $1335-1344$.

[42] R.L. Blakeley, E.C. Webb, B. Zerner, Jack bean urease (EC 3.5.1.5). A new purification and reliable rate assay, Biochemistry 8 (5) (1969) 1984-1990.

[43] L. Mazzei, M. Cianci, S. Benini, S. Ciurli, The structure of the elusive urease-urea complex unveils the mechanism of a paradigmatic nickel-dependent enzyme, Angew. Chemie Int. Ed. 58 (0) (2019) 1-6.

[44] B.P. Roberts, B.R. Miller, A.E. Roitberg, K.M. Merz, Wide-open flaps are key to urease activity, J. Am. Chem. Soc. 134 (24) (2012) 9934-9937.

[45] M.J. Maroney, S. Ciurli, Nonredox nickel enzymes, Chem. Rev. 114 (8) (2014) 4206-4228.

[46] B. Krajewska, W. Zaborska, Jack bean urease: the effect of active-site binding inhibitors on the reactivity of enzyme thiol groups, Bioorg. Chem. 35 (5) (2007) 355-365

[47] B. Krajewska, I. Ureases, Functional, catalytic and kinetic properties: a review, J. Mol. Catal. B Enzym. 59 (1-3) (2009) 9-21.

[48] P.A. Karplus, P.A. Pearson, R.P. Hausinger, 70 years of crystalline ureases: what have we learnt? Acc. Chem. Res. 30 (1997) 330-337.

[49] S. Shah, A. Sharma, M.N. Gupta, Preparation of cross-linked enzyme aggregates by using bovine serum albumin as a proteic feeder, Anal. Biochem. 351 (2) (2006) 207-213

[50] H. Ayhan, F. Ayhan, A. Gulsu, Highly biocompatible enzyme aggregates crosslinked by L-lysine, Turk. J. Biochem. 37 (2012) 14-20.

[51] Q. Zhang, X. Zha, N. Zhou, Y. Tian, Preparation of crosslinked enzyme aggregates (CLEAs) of acid urease with urethanase activity and their application, J. Basic Microbiol. 56 (4) (2016) 422-431.

[52] J. Zdarta, A.S. Meyer, T. Jesionowski, M. Pinelo, A general overview of support materials for enzyme immobilization: characteristics, properties, practical utility, Catalysts 8 (2) (2018) 92.

[53] J.W. Payne, Polymerization of proteins with glutaraldehyde. Soluble molecularweight markers, Biochem. J. 135 (4) (1973) 867-873.

[54] E.C. Valdes, L.W. Soto, G.A. Arcaya, Influence of the $\mathrm{pH}$ of glutaraldehyde and the use of dextran aldehyde on the preparation of cross-linked enzyme aggregates (CLEAs) of lipase from Burkholderia cepacia, Electron. J. Biotechnol. 14 (3) (2011)

[55] B. Krajewska, W. Zaborska, The effect of phosphate buffer in the range of $\mathrm{pH}$ 5.80-8.07 on jack bean urease activity, J. Mol. Catal. B Enzym. 6 (1) (1999) 75-81.

[56] E.L. Carter, N. Flugga, J.L. Boer, S.B. Mulrooney, R.P. Hausinger, Interplay of metal ions and urease, Metallomics 1 (3) (2009) 207-221.

[57] S.N. Drobchenko, L.S. Isaeva-Ivanova, A.R. Kleiner, A.V. Lomakin, A.R. Kolker, V.A. Noskin, An investigation of the structure of periodate-oxidised dextran, Carbohydr. Res. 241 (1993) 189-199.

[58] O. Barbosa, C. Ortiz, Á. Berenguer-Murcia, R. Torres, R.C. Rodrigues, R. Fernandez Lafuente, Glutaraldehyde in bio-catalysts design: a useful crosslinker and a versatile tool in enzyme immobilization, RSC Adv. 4 (4) (2014) 1583-1600.

[59] L. Dal Magro, P.F. Hertz, R. Fernandez-Lafuente, M.P. Klein, R.C. Rodrigues, Preparation and characterization of a Combi-CLEAs from pectinases and cellulases: a potential biocatalyst for grape juice clarification, RSC Adv. 6 (32) (2016) $27242-27251$.

[60] M. Özacar, A.A. Mehde, W.A. Mehdi, Z.Z. Özacar, O. Severgün, The novel multi cross-linked enzyme aggregates of protease, lipase, and catalase production from the sunflower seeds, characterization and application, Colloids Surf. B Biointerfaces 173 (2019) 58-68.

[61] S. Talekar, A. Joshi, G. Joshi, P. Kamat, R. Haripurkar, S. Kambale, Parameters in preparation and characterization of cross linked enzyme aggregates (CLEAs), RSC Adv. 3 (31) (2013) 12485-12511.

[62] Q. Zhen, M. Wang, W. Qi, R. Su, Z. He, Preparation of $\beta$-mannanase CLEAs using macromolecular cross-linkers, Catal. Sci. Technol. 3 (8) (2013) 1937-1941.

[63] J.A. Rupley, E. Gratton, G. Careri, Water and globular proteins, Trends Biochem. Sci. 8 (1) (1983) 18-22.

[64] T.J. Ahern, J.I. Casal, G.A. Petsko, A.M. Klibanov, Control of oligomeric enzyme thermostability by protein engineering, Proc. Natl. Acad. Sci. 84 (3) (1987) $675-679$.

[65] M. van de Weert, W.E. Hennink, W. Jiskoot, Protein instability in poly(lactic-coglycolic acid) microparticles, Pharm. Res. 17 (10) (2000) 1159-1167.

[66] U. Bilati, E. Allemann, E. Doelker, Strategic approaches for overcoming peptide and protein instability within biodegradable nano- and microparticles, Eur. J. Pharm. Biopharm. 59 (3) (2005) 375-388.

[67] R. Varshochian, M. Jeddi-Tehrani, A.R. Mahmoudi, M.R. Khoshayand, F. Atyabi, A. Sabzevari, M.R. Esfahani, R. Dinarvand, The protective effect of albumin on bevacizumab activity and stability in PLGA nanoparticles intended for retinal and choroidal neovascularization treatments, Eur. J. Pharm. Sci. 50 (3-4) (2013) 341-352.

[68] T. Dong, L. Zhao, Y. Huang, X. Tan, Preparation of cross-linked aggregates of aminoacylase from Aspergillus melleus by using bovine serum albumin as an inert additive, Bioresour. Technol. 101 (16) (2010) 6569-6571. 
[69] B.S. Aytar, U. Bakir, Preparation of cross-linked tyrosinase aggregates, Process. Biochem. 43 (2) (2008) 125-131.

[70] I. Migneault, C. Dartiguenave, M.J. Bertrand, K.C. Waldron, Glutaraldehyde: behavior in aqueous solution, reaction with proteins, and application to enzyme crosslinking, Biotechniques 37 (5) (2004) 790-796 798-802.

[71] B. Krajewska, S. Ciurli, Jack bean (Canavalia ensiformis) urease. Probing acid-base groups of the active site by pH variation, Plant Physiol. Biochem. 43 (7) (2005) 651-658.

[72] S. Benini, W.R. Rypniewski, K.S. Wilson, S. Ciurli, S. Mangani, Structure-based rationalization of urease inhibition by phosphate: novel insights into the enzyme mechanism, J. Biol. Inorg. Chem. 6 (8) (2001) 778-790.

[73] J.C.S. dos Santos, N. Rueda, O. Barbosa, M. Millán-Linares, J. Pedroche, M. del Mar Yuste, L.R.B. Gonçalves, R. Fernandez-Lafuente, Bovine trypsin immobilization on agarose activated with divinylsulfone: improved activity and stability via multipoint covalent attachment, J. Mol. Catal. B Enzym. 117 (2015) 38-44.

[74] S.N. Kutcherlapati, N. Yeole, T. Jana, Urease immobilized polymer hydrogel: longterm stability and enhancement of enzymatic activity, J. Colloid Interface Sci. 463 (2016) 164-172.

[75] N. Aissaoui, J. Landoulsi, L. Bergaoui, S. Boujday, J.F. Lambert, Catalytic activity and thermostability of enzymes immobilized on silanized surface: influence of the crosslinking agent, Enzyme Microb. Technol. 52 (6-7) (2013) 336-343.

[76] M. Zeinali, H. Lenjannezhadian, Degradation of urea by entrapped cross-linked urease aggregates: a combinatorial approach to urease stabilization for environmental and industrial applications, Int. J. Environ. Sci. Technol. 15 (1) (2018) 49-56. 